\title{
PREPARO E CARACTERIZAÇÃO DE PROTEÍNAS MIOFIBRILARES DE TILÁPIA-DO-NILO PARA ELABORAÇÃO DE BIOFILMES ${ }^{1}$
}

\author{
EDNELÍ SORAYA MONTERREY-QUINTERO² e PAULO JOSÉ DO AMARAL SOBRAL³
}

\begin{abstract}
RESUMO - A elaboração de filmes comestíveis à base de biopolímeros implica conhecimento das propriedades físico-químicas da macromolécula. Os objetivos deste trabalho foram a descrição de um método de preparo de proteínas miofibrilares de tilápia-do-nilo (Oreochromis niloticus), o estudo das propriedades relacionadas com a formação de filmes, e a caracterização dos biofilmes elaborados com a proteína. Músculo moído de tilápia-do-nilo, recém-abatida, foi lavado e processado até formação de uma pasta homogênea. A evolução das frações protéicas, durante o processamento, foi acompanhada por calorimetria diferencial de varredura. Estudou-se a solubilidade das proteínas miofibrilares liofilizadas (PML) em função do $\mathrm{pH}$ (2-7). A identificação das frações protéicas e dos aminoácidos foi realizada por SDS-PAGE e cromatografia de troca iônica, respectivamente. Os biofilmes formados foram submetidos a testes de perfuração, de solubilidade e microscopia eletrônica. A amostra de PML, constituída apenas de proteínas miofibrilares, apresentou uma região de máxima solubilidade (96,9\%) em torno do $\mathrm{pH} 3,0$ e elevado potencial de interações iônicas $(74,4 \mathrm{~kJ} / 100 \mathrm{~kJ})$. Os biofilmes à base das PML de tilápia-do-nilo são pouco solúveis (abaixo de $20 \mathrm{~g} / 100 \mathrm{~g}$ matéria seca). O glicerol influencia fortemente as propriedades mecânicas e a solubilidade dos biofilmes.
\end{abstract}

Termos para indexação: filmes comestíveis, propriedades funcionais, propriedades mecânicas, solubilidade.

\section{EXTRACTION AND PROPERTIES OF NILE TILAPIA MYOFIBRILLAR PROTEINS FOR EDIBLE FILMS}

\begin{abstract}
The elaboration of edible films based on biopolymers, implies the knowledge of physicochemical properties of macromolecules. The objectives of this work were to describe a methodology of preparing Nile Tilapia myofibrillar proteins and study the properties related to formation and characterization of edible film elaborated with these proteins. Freshly slaughtered ground Nile Tilapia (Oreochromis niloticus) muscle was washed and processed until the formation of a homogeneous paste. Evolution of protein fractions during processing was followed by scanning differential calorimetry. Solubility of freeze-dried myofibrillar proteins was studied as a function of $\mathrm{pH}(2-7)$. Identification of protein fractions and that of the composition of amino acids were accomplished by SDS-PAGE and ion-exchange chromatography, respectively. Biofilms, thus formed, were submitted to puncture, solubility and scanning electron microscopy tests. The sample of freeze-fried proteins, constituted only of myofibrillar proteins, presented maximum solubility $(96.9 \%)$, at $\mathrm{pH}$ around 3 and a high ionic interaction potential $(74.4 \mathrm{~kJ} / 100 \mathrm{~kJ})$. Nile Tilapia myofibrillar protein based biofilms were not very soluble (lower than $20 \mathrm{~g} / 100 \mathrm{~g}$ dry matter). Glycerol strongly influenced mechanical as well as solubility properties of biofilms.
\end{abstract}

Index terms: edible films, functional properties, mechanical properties, solubility.

\footnotetext{
${ }^{1}$ Aceito para publicação em 18 de junho de 1999.

Extraído da Dissertação de Mestrado, apresentada pelo primeiro autor à FZEA-USP, Pirassununga, SP.

${ }^{2}$ Eng. Alimentos, M.Sc., ZAZ-FZEA-USP, Av. Duque de Caxias Norte, 225, CEP 13630-000 Pirassununga, SP

${ }^{3}$ Eng. Alimentos, Dr., ZAZ-FZEA-USP.
}

\section{INTRODUÇÃO}

O acúmulo de embalagens de plástico na natureza tem causado problemas ambientais, nas últimas duas décadas. Uma das soluções encontradas, particularmente na área de embalagens de 
alimentos, é o desenvolvimento de filmes a partir de biopolímeros que possam substituir os materiais sintéticos. Dentre os materiais pesquisados, os biopolímeros naturais, como os polissacarídeos e as proteínas, se apresentam mais promissores, em razão de serem abundantes, renováveis, econômicos, e capazes de formar uma matriz contínua (Gontard \& Guilbert, 1996). Esses biopolímeros, além de biodegradáveis, proporcionam embalagens comestíveis, quando não sujeitos a modificações químicas e quando adicionados somente de aditivos de grau alimentício.

As características estruturais e a composição química do biopolímero utilizado na elaboração dos biofilmes são muito importantes. Nesse sentido as proteínas são mais interessantes que os polissacarídeos (homopolímeros), por possuírem em sua estrutura até 20 monômeros diferentes (aminoácidos), com alto potencial de interações intermoleculares (Gontard \& Guilbert, 1996). Segundo Cuq (1996b), as propriedades funcionais (força, deformação, barreira aos gases, etc.) dos biofilmes dependem sobretudo do tipo de ligações intermoleculares.

Observa-se, na literatura, que as proteínas mais estudadas são as de origem vegetal, possivelmente pela alta produção e baixo custo nos países desenvolvidos. No Brasil, a única proteína vegetal disponível em abundância e economicamente competitiva é a proteína de soja. Por outro lado, as proteínas de origem animal são produzidas a baixo custo, em relação ao primeiro mundo. No caso particular de peixe de cultivo, a oferta é crescente e com potencial muito grande.

De modo geral, as proteínas vegetais são comercializadas purificadas. Das proteínas de origem animal, apenas a gelatina é comercializada desta forma. Logo, a utilização de proteínas miofibrilares de peixe implica o seu preparo antes da elaboração dos biofilmes. Normalmente, a extração de proteínas miofibrilares do músculo animal é realizada empregando-se soluções salinas, para dissolução das proteínas, e centrifugação, para separação das frações solubilizadas, técnica essa conhecida como centrifugação diferencial (Huf-Lonergan et al., 1994). Essas técnicas não são interessantes para o preparo de matéria-prima para biofilmes, porque o fracionamento das miofibrilas não é necessário, e a presença de sais pode ser indesejável. Como o biofilme é um material de baixa umidade, os sais podem cristalizar.

A necessidade da adição de cloreto de sódio para a solubilização das proteínas musculares contráteis é uma prática que vem sendo superada. Vários pesquisadores (Wu et al., 1991; Stefansson \& Hultin, 1994; Venugopal et al., 1995) têm demonstrado que, quando intensivamente lavadas, essas proteínas possuem elevada solubilidade em água. Wu et al. (1991) sugerem que as lavagens removem algumas proteínas solúveis, bem como outros componentes de baixo peso molecular, que possivelmente interagem com as proteínas miofibrilares, impedindo sua solubilização.

Um dos processos mais amplamente utilizados na elaboração de biofilmes, é o casting, que compreende o preparo de uma solução coloidal da macromolécula e aditivos, aplicação dessa solução num suporte adequado, seguida de secagem em condições estritamente controladas. Dessa forma, para a elaboração de biofilmes a partir de novas matérias-primas biológicas, é necessário, inicialmente, a obtenção do biopolímero e o conhecimento de suas propriedades, principalmente da sua solubilidade em água e sua capacidade de interação intermolecular.

Cuq et al. (1995), trabalhando com sardinhas (Sardina pilchardus), demonstraram que as proteínas miofibrilares possuem a capacidade de formar filmes transparentes e bastante resistentes. Outros trabalhos foram realizados com proteínas miofibrilares de carne bovina (Souza et al., 1997; Ocuno et al., 1998) e de peixe (Monterrey-Quintero, 1998). Nesses estudos são evidenciadas as características promissoras desses materiais e a necessidade de mais pesquisas para melhor desenvolvimento dos filmes.

Este trabalho teve como objetivos: a apresentação de um método de preparo de proteínas miofibrilares de tilápia-do-nilo para emprego na elaboração de biofilmes; o estudo das propriedades funcionais das proteínas relacionadas com a formação de filmes; e a caracterização dos biofilmes formados. 


\section{MATERIAL E MÉTODOS}

\section{Preparo das proteínas miofibrilares}

Foram utilizadas tilápias-do-nilo criadas no Laboratório de Aqüicultura da FZEA-USP, Pirassununga. Os peixes, recém capturados, foram conduzidos vivos para o Laboratório de Tecnologia de Alimentos, onde foram abatidos, eviscerados e filetados. O preparo das proteínas miofibrilares foi realizado em seguida, para possibilitar a produção de proteínas pré rigor mortis, seguindo-se uma metodologia empregada no preparo de proteínas para o surimi (Verrez et al., 1988). O músculo, sem espinhas, foi moído, e em seguida, lavado por quatro vezes com água destilada a $5^{\circ} \mathrm{C}$, na proporção músculo:água de $1: 2$, descartando-se sempre o sobrenadante. O músculo lavado foi cominuído durante dez minutos, para formação de uma pasta homogênea. Essas operações foram realizadas em um processador de alimentos, com acessórios simulando um moedor, um agitador (para lavagem) e um cutter. Em seguida, a pasta foi passada em peneira fina (ABNT 30-0,59 mm), para eliminação do tecido conectivo (Verrez et al., 1988). A pasta de proteínas miofibrilares (PPM) assim obtida, foi congelada com $\mathrm{N}_{2}$ líquido e liofilizada (Hetotrap CT-60e), obtendo-se as proteínas miofibrilares liofilizadas (PML), que foram analisadas (proteína, gordura e cinzas) segundo os métodos da Association of Official Analytical Chemists (1995).

\section{Análise térmica}

A evolução do processo de preparo das PML foi acompanhada por análise entálpica de varredura. Até a obtenção da PPM, foram retiradas amostras, em duplicata, dos vários estágios: músculo intacto, músculo moído e lavado, músculo cominuído, pasta de proteínas miofibrilares. O excesso de água foi retirado por centrifugação (FANEM Excelsa Baby II Mod. 206-R) a $1500 \mathrm{rpm}$, durante 15 minutos (Park \& Lanier, 1989).

As análises foram realizadas num calorímetro diferencial de varredura (DSC 2010, TA Instruments), com amostras da ordem de $10 \mathrm{~g}$ (balança analítica Scientech SA-210, com precisão de $0,0001 \mathrm{~g}$ ) em cápsulas de alumínio herméticas. Como referência foi utilizada uma cápsula vazia. A faixa de temperatura varrida foi de $0-100^{\circ} \mathrm{C}$, a $10^{\circ} \mathrm{C} /$ minuto (Hastings et al., 1985 ; Park \& Lanier, 1989), sob fluxo de $\mathrm{N}_{2}$ de $100 \mathrm{~mL} /$ minuto

\section{Solubilidade em água das proteínas miofibrilares}

A solubilidade em água das proteínas miofibrilares foi determinada segundo Stefansson \& Hultin (1994). Dois gramas de PML foram dissolvidos em $30 \mathrm{~mL}$ de água. $\mathrm{O} \mathrm{pH}$ foi em seguida ajustado com ácido acético glacial (Synth PA - ACS) ou hidróxido de sódio (Vetec $\mathrm{NaOH}$ - PA), controlado com um peagâmetro de bancada (TECNAL - TEC 2). O peso total foi completado para $100 \mathrm{~g}$ com água destilada. A solução foi agitada à temperatura ambiente $\left(22^{\circ} \mathrm{C}\right)$ durante 30 minutos, e centrifugada (Beckman Mod. J2-21) a $37.000 \mathrm{G}$, por 20 minutos, à temperatura de $4{ }^{\circ} \mathrm{C}$. $\mathrm{O}$ teor de proteínas das soluções centrifugadas (proteína total) e dos sobrenadantes (proteína solúvel) foi determinado, em duplicata, pelo método micro Kjeldahl ( $\mathrm{N} \times$ 6,25). A solubilidade foi calculada como a relação entre a proteína solúvel e a proteína total expressa em porcentagem ( $\mathrm{g}$ de proteína solúvel/100 g proteína total). O ensaio foi realizado em triplicata.

\section{Eletroforese em SDS-PAGE da amostra de proteínas miofibrilares}

A caracterização das frações de proteínas miofibrilares foi realizada por eletroforese em gel de poliacrilamida na presença de dodecil sulfato de sódio (SDS-PAGE). Foram utilizadas amostras de proteínas miofibrilares liofilizadas de espécimens jovens e adultos de tilápia-donilo. As amostras foram desnaturadas a $95^{\circ} \mathrm{C}$ por cinco minutos em solução de $\beta$-mercaptoetanol; Tris- $\mathrm{HCl} \quad 0,5$ $\mathrm{M}(\mathrm{pH} 6,8)$; glicerol; SDS $10 \%(\mathrm{p} / \mathrm{v})$; azul de bromofenol $0,1 \%(\mathrm{p} / \mathrm{v})$. A eletroforese foi conduzida em gel (SDS-PAGE) com gradiente de 6-15\%, imerso em solução-tampão Tris $0,025 \mathrm{M}$; glicina $0,192 \mathrm{M}$; SDS $0,1 \%$ ( $\mathrm{pH} 8,3$ ). Para a identificação das proteínas presentes nas amostras, foram utilizados padrões BIO RAD. As bandas foram reveladas com o corante Coomassie-G-250. A determinação das frações protéicas foi realizada por densitometria (SHARP, JX330).

\section{Composição de aminoácidos da amostra de proteínas miofibrilares}

Para a determinação do perfil de aminoácidos da PML, foi seguido o procedimento descrito por Cândido (1998). Após hidrólise ácida, filtração e diluição, alíquotas foram injetadas numa coluna de troca iônica, com posterior reação com ninidrina. O produto da reação foi quantificado num colorímetro.

Com base na classificação dos aminoácidos em hidrofóbicos, polares ionizados e polares não ionizados, além da ponte de dissulfeto, calcularam-se as contribuições energéticas teóricas de cada grupo nas diversas interações, utilizando-se os valores sugeridos por Cuq (1996a): $8 \mathrm{~kJ} / \mathrm{mol}$ para as interações hidrofóbicas, 
$62 \mathrm{~kJ} / \mathrm{mol}$ para as interações iônicas, $25 \mathrm{~kJ} / \mathrm{mol}$ para as pontes de hidrogênio e $350 \mathrm{~kJ} / \mathrm{mol}$ para as pontes dissulfeto.

\section{Elaboração dos biofilmes}

Os biofilmes à base das PML foram elaborados segundo estudos prévios (Monterrey-Quintero, 1998): pH 2,5; concentração de proteína de $1,25 \%$ (g/100 g de solução); concentração de glicerol na faixa de 30,50 e $70 \%$ (g/100 g de proteína). As soluções filmogênicas (SF) foram preparadas pela dispersão das proteínas miofibrilares em água destilada e posterior adição de glicerol (Synth P.A.-ACS), sob agitação moderada. $\mathrm{O}$ pH da solução foi controlado com ácido acético glacial (Synth P.A.-ACS) As SF foram mantidas em banho-maria a $40^{\circ} \mathrm{C}$, durante 30 minutos, sendo, em seguida, tratadas em banho de ultra-som, por dez minutos, para eliminação de bolhas Posteriormente, a SF foi aplicada em placas de plexiglass $\left(138,42 \mathrm{~cm}^{2}\right)$ e submetida a secagem em estufa com circulação e renovação de ar $\left(30^{\circ} \mathrm{C} / 24\right.$ horas). Após a secagem, os filmes foram condicionados em ambiente com UR $=58 \%$ e $\mathrm{T}=22^{\circ} \mathrm{C}$, durante quatro dias. A espessura dos filmes foi controlada fixando-se o peso da matéria-seca (proteína e glicerol) depositada em cada placa, em $5 \mathrm{mg} / \mathrm{cm}^{2}$, obtendo-se assim, filmes com espessura média de $0,045 \mathrm{~mm}( \pm 0,004 \mathrm{~mm})$. A espessura dos filmes foi medida (média de nove determinações) com um micrômetro digital ( $\pm 0,001 \mathrm{~mm}$ ), com superfície de contato de $6,4 \mathrm{~mm}$ de diâmetro. A umidade de todos filmes foi determinada pelo método descrito pela Association of Official AnalyticaL Chemists (1995).

\section{Caracterização dos biofilmes}

As propriedades mecânicas dos filmes foram determinadas por teste de perfuração, utilizando-se um texturômetro TA.XT2i (Stable Micro Systems) (Gontard, 1991). Os filmes foram fixados em uma célula $(\phi=52,6 \mathrm{~mm})$, e uma sonda cilíndrica de $3 \mathrm{~mm}$ de diâmetro foi forçada $(1 \mathrm{~mm} / \mathrm{s})$ perpendicularmente à superfície do filme. A força (F) na ruptura e o deslocamento (D) foram obtidos diretamente das curvas de força $v s$ deformação, com o emprego do programa Texture Expert 1.15 (Stable Micro Systems). A deformação na ruptura $\left(\Delta l / l_{o}\right)$ foi calculada com a equação 1 , sendo $l_{o}$ o comprimento inicial do filme, calculado como o raio da célula de medida $(26,3 \mathrm{~mm})$ :

$\frac{\Delta l}{l_{0}}=\frac{\left(\sqrt{D^{2}+l_{0}^{2}}-l_{0}\right) \times 100}{l_{0}}$
A opacidade aparente dos filmes foi determinada com a ajuda de um espectrofotômetro (BECKMAN DU 640), como proposto por Gontard (1991). Os filmes foram cortados em retângulos e aderidos à parede interna da cubeta do espectrofotômetro. Nessas condições, foi varrida a faixa do comprimento de onda da luz visível, de 400 a $800 \mathrm{~nm}$. Foi traçada, para cada filme, a curva absorbância $v s$ comprimento de onda, e a opacidade foi calculada como a área sob a mesma (determinada por integração) expressa nas unidades correspondentes (Abs.nm).

Para determinação da solubilidade, foram recortados dois discos dos filmes ( $2 \mathrm{~cm}$ de diâmetro) de umidade conhecida, pesados e imersos em $50 \mathrm{~mL}$ de água destilada. Após 24 horas, a $22^{\circ} \mathrm{C}$, sob agitação, foi determinado o conteúdo de matéria seca não solubilizada dos filmes. A matéria seca dos filmes foi determinada em estufa a vácuo a $95^{\circ} \mathrm{C}$, durante 48 horas. Todos os testes acima descritos foram realizados em sala com temperatura controlada, a $22^{\circ} \mathrm{C}$ e umidade relativa ambiente

Foi examinada também a microestrutura de biofilmes contendo 30 e $70 \%$ de glicerol. Para a avaliação da seção transversal dos filmes, estes foram imersos em nitrogênio líquido e fraturados. As amostras de filmes foram desidratadas a vácuo durante 36 horas, colocadas em suportes de cobre e recobertas de ouro (Sputter Coater, SCD050) para melhorar a condutibilidade. As amostras foram analisadas em um microscópio eletrônico de varredura (JEOL - JXA-840A)

\section{RESULTADOS E DISCUSSÃO}

As análises bromatológicas realizadas na amostra de proteínas miofibrilares liofilizadas evidenciaram a seguinte composição média em relação à matéria seca: 93,22\% de proteína; $2,40 \%$ de gordura e $1,69 \%$ de cinzas. Esses resultados estão de acordo com análises de proteínas miofibrilares liofilizadas de tilápia-do-nilo, submetidas a diferentes tratamentos, realizadas por Cândido (1998): 84,1\% a 97,7\% de proteína; $1,1 \%$ a $5,1 \%$ de gordura; $0,1 \%$ a $0,5 \%$ de carboidratos e $1,99 \%$ a $12,7 \%$ de cinzas, em base seca.

\section{Análise térmica}

Os termogramas das amostras nas diversas etapas do processo de preparo da pasta de proteínas miofibrilares (músculo intacto, músculo moído e lavado, músculo cominuído, pasta de proteínas 
miofibrilares), obtidos no DSC, estão apresentados na Fig. 1. Tomou-se como temperatura de desnaturação das diversas frações de proteínas, a temperatura onde ocorreu o pico da endoterma. As respectivas temperaturas, calculadas como a média entre quadruplicatas, estão apresentadas na Tabela 1.

No termograma do músculo intacto (A) podem ser observadas três endotermas: a $41,1^{\circ} \mathrm{C}$ ocorre a desnaturação de frações de proteínas sarcoplasmáticas e do colágeno; a $54,4^{\circ} \mathrm{C}$ ocorre a desnaturação da miosina, podendo também ocorrer a desnaturação de outras frações das proteínas sarcoplasmáticas, e a $75,9^{\circ} \mathrm{C}$, a desnaturação da actina (Hastings et al., 1985). A remoção das proteínas sarcoplasmáticas através das lavagens

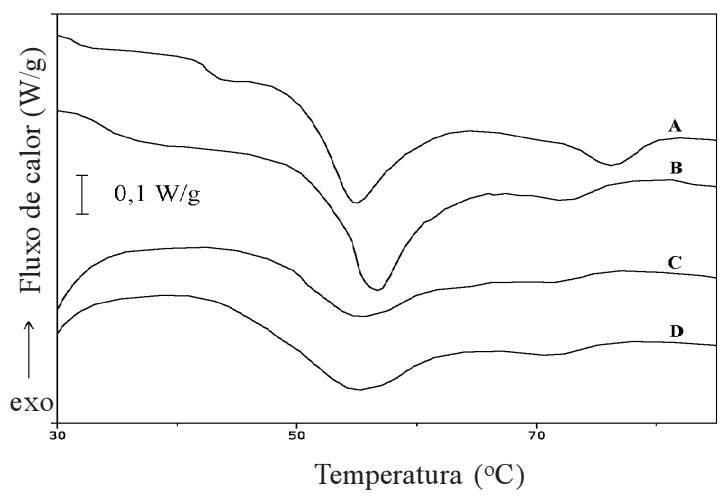

FIG. 1. Termogramas das etapas de extração das proteínas miofibrilares: A) músculo intacto; B) músculo moído e lavado; C) músculo cominuído; D) pasta de proteínas miofibrilares. pode ser confirmada nos outros termogramas, onde só aparecem duas transições, referentes à miosina $\left(55-56^{\circ} \mathrm{C}\right)$ e à actina $\left(71-72^{\circ} \mathrm{C}\right)$, demonstrando-se, assim, a obtenção das proteínas miofibrilares.

Park \& Lanier (1989), trabalhando com outra variedade de tilápia (Oreochromis aureus), determinaram que a miosina desnatura a $58,3^{\circ} \mathrm{C}$ e a actina, a $78,6^{\circ} \mathrm{C}$. As diferenças de valores de temperatura deve ser atribuída à diferença nas espécies das tilápias e diferenças na metodologia.

A redução da temperatura de transição da actina, de $75,9^{\circ} \mathrm{C}$ no músculo intacto, para valores da ordem de $72^{\circ} \mathrm{C}$ (Tabela 1), após a trituração e lavagem, é um fenômeno relatado na bibliografia. Park \& Lanier (1989) observaram uma redução de $78,6^{\circ} \mathrm{C}$ para $74,0^{\circ} \mathrm{C}$ na temperatura de desnaturação da actina, durante o processo de produção de surimi de tilápia (Oreochromis aureus). No caso da miosina, o fenômeno ocorre no sentido contrário, mas de maneira mais sutil. Esses fenômenos ainda são difíceis de serem explicados, mas devem ser conseqüência da destruição de certas interações entre as miofibrilas, que tornavam essas proteínas mais estáveis termicamente.

\section{Solubilidade das proteínas miofibrilares}

A variação da concentração de proteína na solução, em função do $\mathrm{pH}$, pode ser observada na Fig. 2, onde cada ponto corresponde à média de três determinações. Em pH abaixo de 3,0 a solubilidade atinge o valor de $96,9 \%( \pm 4,2)$ de proteínas em solução. É observado um ponto de mínima solubilidade $(11,76 \pm 4,78 \%$ ) próximo de $\mathrm{pH} 5,5$, que deve corresponder ao ponto isoelétrico das proteínas em questão. Esse comportamento já foi relatado por

TABELA 1. Temperaturas ${ }^{1}\left({ }^{\circ} \mathrm{C}\right)$ de desnaturação das proteínas de tilápia-do-nilo.

\begin{tabular}{lccc}
\hline Etapa do processo & & Proteínas & \\
\cline { 2 - 5 } & Sarcoplasmáticas & Miosina & Actina \\
\hline Músculo intacto & $41,1 \pm 0,9$ & $54,4 \pm 0,2$ & $75,9 \pm 0,3$ \\
Músculo moído e lavado & - & $56,2 \pm 1,0$ & $72,2 \pm 0,8$ \\
Músculo cominuído & - & $55,2 \pm 0,7$ & $71,7 \pm 0,3$ \\
Pasta de proteínas miofibrilares & - & $55,6 \pm 0,8$ & $71,1 \pm 0,8$ \\
\hline
\end{tabular}

1 Temperatura dos picos dos termogramas (média de quatro repetições \pm desvio-padrão).

${ }^{2}$ Fonte: Hastings et al. (1985). 


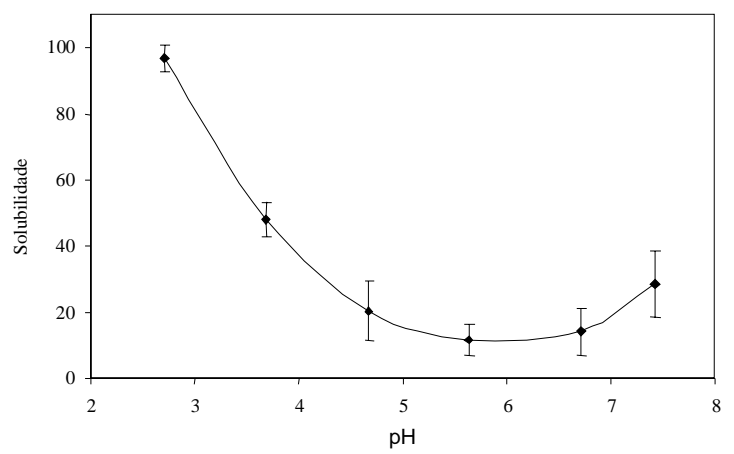

FIG. 2. Solubilidade (g de proteína em solução/100 g de proteína total) das proteínas miofibrilares liofilizadas em função do pH. vários autores (Meinke et al., 1972; Stefansson \& Hultin, 1994) e é explicado pelo efeito da variação do balanço iônico das proteínas, em função do $\mathrm{pH}$.

\section{Eletroforese em SDS-PAGE}

Os resultados das análises de eletroforese SDS-PAGE, com gradiente de 6 a $15 \%$, de PML preparadas a partir de A) espécimens jovens $(160$ - $230 \mathrm{~g})$ e B) adultos (300 - $400 \mathrm{~g})$ e do padrão BIORAD (P), estão apresentados na Fig. 3.I, onde se pode verificar que as duas amostras (A e B) apresentam um perfil eletroforético semelhante.

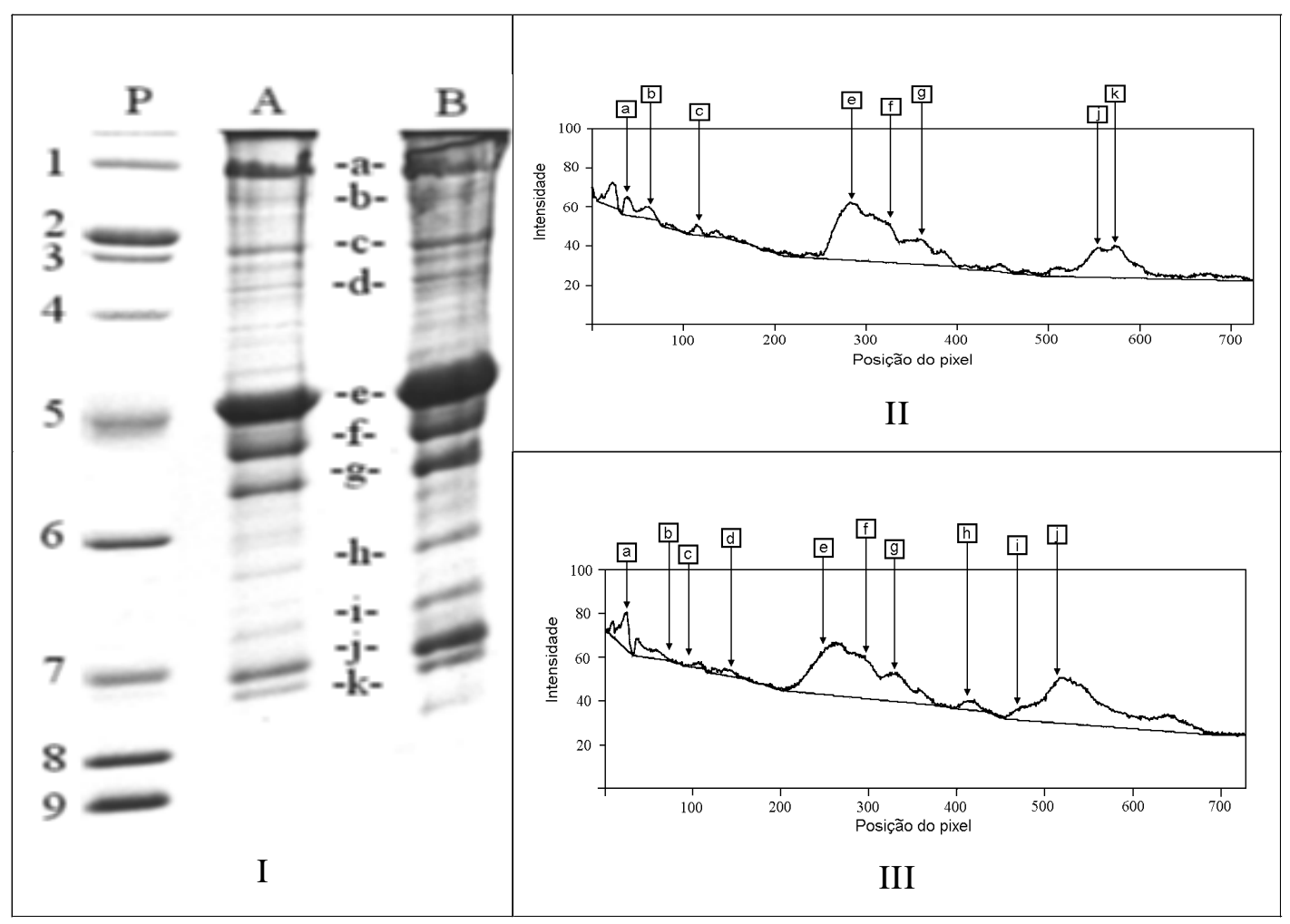

FIG.3. I. Eletroforetograma em gel SDS-PAGE das amostras de proteínas miofibrilares de tilápia-do-nilo: P-padrões BIO RAD (1- miosina (200 kDa); 2 - $\beta$-galactosidade $(116,25 \mathrm{kDa})$; 3- Fosforilase b (97,4 kDa); 4- Albumina sérica (66,2 kDa); 5- Ovalbumina (45 kDa); 6- anidrase carbônica (31 kDa); 7- inibidor de tripsina $(21,5 \mathrm{kDa})$; 8- lisozima $(14,4 \mathrm{kDa})$ e 9- aprotinina (6,5 kDa)); A- tilápia jovem (160-230 g); B- tilápia adulta (300-400 g); II. densitometria da eletroforese das proteínas miofibrilares de tilápia-do-nilo jovem; III. densitometria da eletroforese das proteínas miofibrilares de tilápia-do-nilo adulta. 
Os resultados das análises por densitometria dos géis obtidos por SDS-PAGE estão apresentados na Fig. 3.II e 3.III, permitindo a identificação das diversas frações protéicas presentes nas amostras. As letras minúsculas correspondem às bandas protéicas. Os pesos moleculares das bandas protéicas são apresentados na Tabela 2. Entre as frações protéicas presentes, foram identificadas as que caracterizam as proteínas miofibrilares, isto é, as proteínas contráteis actina e miosina: cadeias de miosina de alto peso molecular (banda a); fragmentos de miosina de alto peso molecular (banda b); actina (banda e) e cadeias leves de miosina (bandas h e k).

Os resultados obtidos são muito semelhantes aos observados por Cuq et al. (1995) em densitometria de SDS-PAGE de soluções filmogênicas à base de proteínas miofibrilares de sardinha (Sardinha pilchardus). A identificação das bandas foi praticamente a mesma, com a única diferença que esses autores não separaram a troponina e a tropomiosina em suas subunidades. As figuras de SDS-PAGE apresentadas por An et al. (1994) trabalhando com amostras de surimi de merluza (Merluccius productus), mostram também um perfil eletroforético muito parecido, com a diferença de que não foram observadas as bandas relativas à $\alpha$-actinina e as troponinas C e I. As diferenças devem-se principalmente às diferentes concentrações do gel utilizadas, gradiente de 3,2-17,4\% por Cuq et al. (1995), 10\% no trabalho de An et al. (1994) e gradiente de $6-15 \%$ no presente trabalho.

TABELA 2. Identificação das bandas observadas na eletroforese em SDS-PAGE.

\begin{tabular}{cccc}
\hline Banda & \multicolumn{2}{c}{ Peso molecular (Da) } & Proteína $^{1}$ \\
\cline { 2 - 3 } & $\begin{array}{c}\text { Tilápia } \\
\text { jovem }\end{array}$ & $\begin{array}{c}\text { Tilápia } \\
\text { adulta }\end{array}$ & \\
\hline a & 151.980 & 163.878 & CPM \\
b & 137.943 & 130.713 & Fragmento CPM \\
c & 108.849 & 118.641 & $\alpha$-actinina \\
d & - & 96.691 & Fragmento CPM \\
e & 52.908 & 61.516 & Actina \\
f & 44.058 & 49.812 & $\beta$-tropomiosina e troponina T \\
g & 37.893 & 43.586 & $\alpha$-tropomiosina \\
h & - & 30.552 & CLM \\
i & - & 23.850 & Troponina I \\
j & 16.538 & 19.648 & Troponina C \\
k & 15.338 & - & CLM \\
\hline CPM: cadeias pesadas de miosina; CLM. cadeias leves de miosina
\end{tabular}

1 CPM: cadeias pesadas de miosina; CLM: cadeias leves de miosina.
O número e intensidade de bandas correspondentes a fragmentos de miosina de alto peso molecular, se devem à preservação das proteínas miofibrilares da ação das catepsinas. Estudos feitos por Jiang et al. (1997) com peixes (Scomber australasicus) preparados para surimi demonstram que as catepsinas B e L conservam $82 \%$ da sua atividade enzimática após congelamento, por oito semanas, a $-40^{\circ} \mathrm{C}$. Pode-se, então, supor que, a conservação das proteínas miofibrilares das amostras é devida à liofilização e não ao congelamento. Esta é uma grande vantagem do método de conservação utilizado, que já tinha sido evidenciado anteriormente pelos altos valores de solubilidade da amostra liofilizada.

Composição de aminoácidos das proteínas miofibrilares

O perfil de aminoácidos da amostra de proteínas miofibrilares de tilápia-do-nilo está apresentado na Tabela 3. As maiores concentrações presentes são de ácido aspártico (12,08\%), ácido glutâmico

TABELA 3. Composição de aminoácidos das proteínas miofibrilares de tilápia-do-nilo.

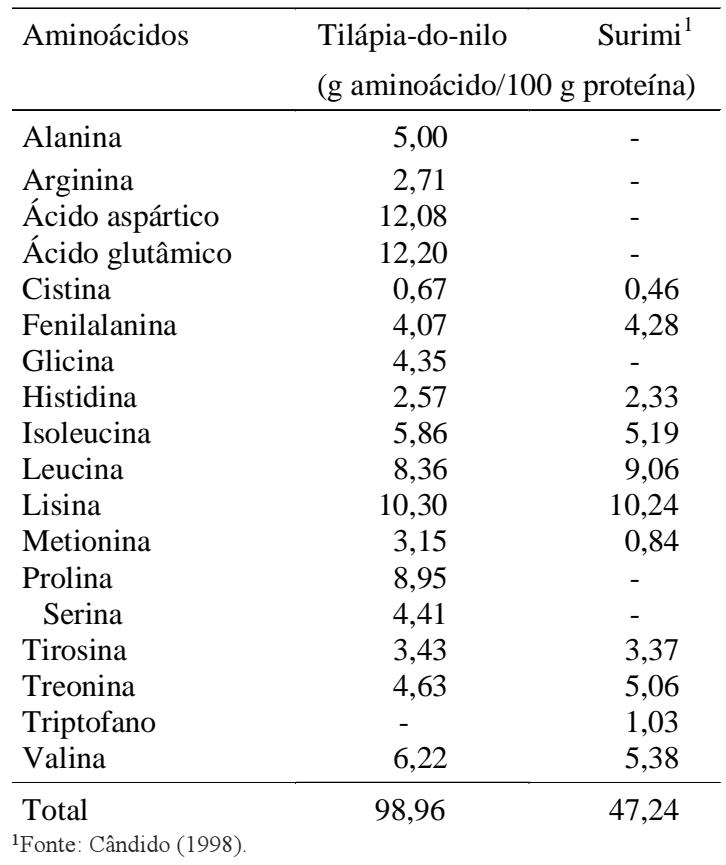


$(12,2 \%)$, lisina $(10,30 \%)$ e prolina $(8,95 \%)$. Observa-se uma concentração muito baixa de cistina $(0,67 \%)$, o que implica uma baixa densidade de ligações dissulfeto (-S-S-). A ausência de asparagina e de glutamina deve-se à sua degradação durante a hidrólise ácida a que foi submetida a amostra para a análise, evidenciada pela presença de amônia $(1,04 \%)$. O triptofano também é perdido nesta operação.

Quando se compara a composição de aminoácidos da amostra de proteínas miofibrilares de tilápiado-nilo obtida nesta pesquisa, com os resultados de aminoácidos essenciais, apresentados por Cândido (1998), para surimi (concentrado de proteínas miofibrilares adicionado de crioprotetores) à base de proteínas de peixes da mesma espécie, são observados valores muito próximos, com exceção da metionina, que teve menor concentração no surimi $(0,84 \mathrm{~g} / 100 \mathrm{~g}$ proteína) na sua forma isolada, em relação à amostra desta pesquisa $(3,15 \mathrm{~g} / 100 \mathrm{~g}$ proteína), por ter sido determinado também conjugado com a cisteína (Met-Cys: 1,3 g/100 g proteína).

A partir do perfil de aminoácidos, foi possível o cálculo da energia envolvida nas interações intermoleculares de naturezas diferentes: interações hidrofóbicas, $370,4 \mathrm{~kJ} / 100 \mathrm{~mol}$ de aminoácidos; interações iônicas, $2201,0 \mathrm{~kJ} / 100 \mathrm{~mol}$ de aminoácidos; pontes de hidrogênio, $259,7 \mathrm{~kJ} / 100 \mathrm{~mol}$ de aminoácidos e pontes de dissulfeto, 126,3 kJ/100 mol de aminoácidos. Dessa forma, as interações mais intensas, do ponto de vista energético, são as interações iônicas, representando $74,4 \%$ das interações potenciais, seguidas pelas interações hidrofóbicas $(12,5 \%)$ e pontes de hidrogênio $(8,8 \%)$. Resultado similar pode ser visto no trabalho de Cuq (1996a), com proteínas miofibrilares de sardinha. A alta densidade de interações iônicas, juntamente com as pontes de hidrogênio, contribuem para a alta solubilidade em água, da amostra de proteínas miofibrilares de tilápia-do-nilo, em baixo $\mathrm{pH}$.

\section{Caracterização dos biofilmes}

De maneira geral, os filmes produzidos com as PML, nas condições descritas $(\mathrm{pH} 2,5$; concentração de proteína: $1,25 \mathrm{~g} / 100 \mathrm{~g}$ de solução e concentração de glicerol: 30-70 g/100 g de proteína), apresentaram-se transparentes, incolores, com bom aspecto e manuseáveis.

Observa-se, na Tabela 4, que a força necessária à ruptura dos biofilmes variou de $2,94 \mathrm{~N}$ no filme com $70 \%$ de glicerol para $6,67 \mathrm{~N}$ no filme com $30 \%$ de glicerol. Inversamente, a deformação na ruptura apresentou valor de $2,71 \%$ no biofilme com $30 \%$ de glicerol e de $7,50 \%$ no biofilme com $70 \%$ de glicerol, o que indica a forte influência do plasticizante sobre as propriedades mecânicas desses materiais. A diminuição da força e o aumento da deformação na ruptura com o aumento do plasticizante são comportamentos típicos dos biofilmes (Gontard, 1991; Cuq et al., 1995; Parris et al., 1995). A presença de plasticizantes diminui a densidade das interações proteína-proteína aumentando a mobilidade das cadeias polipeptídicas e tornando os filmes menos resistentes e mais deformáveis (Cuq, 1996a, 1996b).

Os filmes de proteínas miofibrilares de tilápia-donilo apresentaram maior força e menor deformação na ruptura do que filmes à base de glúten de trigo, que atingem máximos de 3,13 N (pH 3,0; glúten, $10 \mathrm{~g} / 100 \mathrm{~mL}$ de solução; glicerol, $20 \mathrm{~g} / 100 \mathrm{~g}$ de glúten) e 13,2\% (pH 2,0; glúten, 7,5 g/100 mL de solução; glicerol, 20 g/100 g de glúten) (Gontard, 1991)

TABELA 4. Caracterização dos biofilmes em função da concentração de glicerol.

\begin{tabular}{ccccc}
\hline $\begin{array}{c}\text { Glicerol } \\
\text { (g/100 g proteína) }\end{array}$ & $\begin{array}{c}\text { Força } \\
\text { na ruptura }(\mathrm{N})\end{array}$ & $\begin{array}{c}\text { Deformação } \\
\text { na ruptura }(\%)\end{array}$ & $\begin{array}{c}\text { Opacidade aparente } \\
(\text { Abs.nm })\end{array}$ & $\begin{array}{c}\text { Solubilidade } \\
(\mathrm{g} / 100 \mathrm{~g} \text { MS })\end{array}$ \\
\hline 30 & 6,67 & 2,71 & 26,1 & 12,30 \\
50 & 4,65 & 4,76 & 22,8 & 15,89 \\
70 & 2,94 & 7,50 & 23,9 & 19,50 \\
\hline
\end{tabular}


Os valores da opacidade aparente também estão listados na Tabela 4. A opacidade aparente apresentou valor mínimo de $22,8 \mathrm{Abs} . \mathrm{nm}$ (50\% de glicerol), e, máximo, de 26,1 Abs.nm (30\% de glicerol). A baixa opacidade de biofilmes à base de proteínas miofibrilares já foi relatada em estudo de filmes feitos à partir de proteínas miofibrilares de sardinha (Sardina pilchardus) (Cuq et al., 1995). Tal fato fica evidente quando se compara a opacidade aparente desses biofilmes com, por exemplo, os filmes à base de glúten de trigo que podem apresentar opacidade aparente de até 250,4 Abs.nm (Gontard, 1991).

Quanto à solubilidade, os filmes mantiveram sua integridade após a imersão em água durante 24 horas, sob agitação constante, o que indica que a rede protéica se manteve intacta. Os valores de solubilidade obtidos, possivelmente devido às frações protéicas de baixo peso molecular e sobretudo à glicerina, estão listados na Tabela 4. Como esperado, a solubilidade apresentou uma correlação positiva $\left(\mathrm{R}^{2}=0,993\right)$ com a concentração de glicerol, com valor mínimo de $12,3 \%$ (bs) e máximo de $19,5 \%$ (bs), correspondentes aos extremos de glicerol: $30 \%$ e $70 \%(\mathrm{~g} / 100 \mathrm{~g}$ de proteína), respectivamente. A solubilidade dos filmes à base de proteínas miofibrilares de tilápia-do-nilo, apresenta valores inferiores aos da maioria dos biofilmes protéicos relatados na literatura, como, por exemplo, filmes à base de proteínas miofibrilares de sardinha, com solubilidade na faixa de $33 \%$ a $47 \%$ em filmes com $35 \%$ (bs) de glicerol (Cuq et al., 1996); de concentrado protéico de arroz, com $35,3 \%$ a $76,4 \%$ de solubilidade (Shih, 1996); de isolado protéico de soro de leite, com valores acima de 50\% (Failey et al., 1996); de isolado protéico de soja, com solubilidade na faixa de $26,81 \%$ a $39,41 \%$ (Kunte et al., 1997) e glúten de trigo, com valores de $31,5 \%$ a $100 \%$ (Gontard, 1991).

A menor solubilidade dos filmes à base de tilápia-do-nilo, comparada com a solubilidade dos filmes à base de proteínas (pós rigor mortis) de sardinha (Cuq et al., 1996), é devido ao fato de que neste trabalho utilizou-se proteína pré rigor mortis. No primeiro caso, ocorreu a formação de cadeias polipeptídicas menores, portanto, mais solúveis. A influência do tamanho das frações protéicas na solubilidade de biofilmes é relatada por Kunte et al. (1997) em filmes à base de isolados protéicos de soja, que observaram um aumento da solubilidade com a utilização de frações protéicas de menor peso molecular.

Os resultados da microscopia eletrônica dos biofilmes contendo $30 \%$ e $70 \%$ de glicerol estão apresentados nas Figs. 4 e 5, respectivamente. Pode-se observar que a matriz dos biofilmes é densa. Esse caráter compacto pode ser responsável pelos baixos valores de solubilidade em água

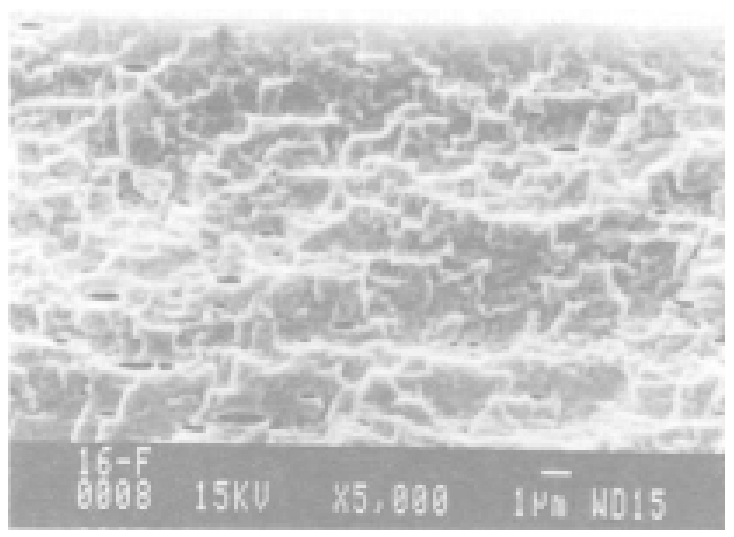

FIG. 4. Micrografia da fratura do biofilme contendo $30 \%$ de glicerol, vista com ampliação de 5.000x.

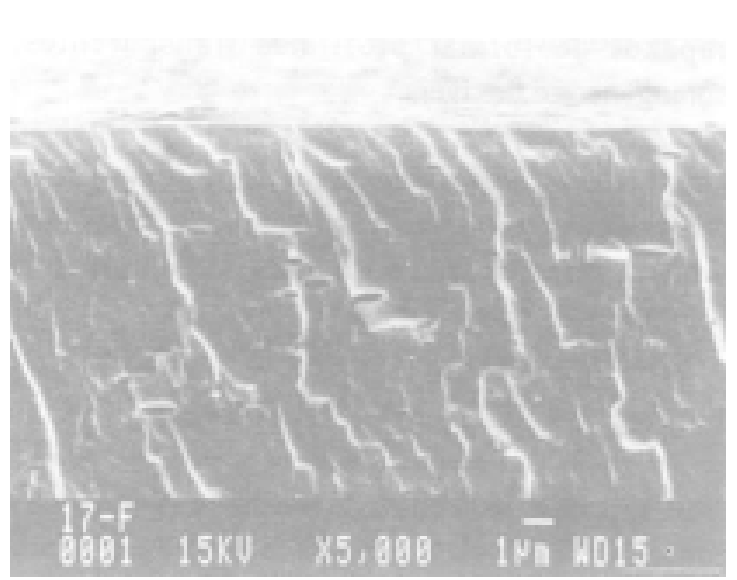

FIG. 5. Micrografia da fratura do biofilme contendo $70 \%$ de glicerol, vista com ampliação de $5.000 x$.

Pesq. agropec. bras., Brasília, v.35, n.1, p.179-189, jan. 2000 
apresentados pelos biofilmes de proteínas miofibrilares de tilápia-do-nilo. Gontard (1991), trabalhando com biofilmes à base de glúten, observou, através de micrografias, que os filmes com microestrutura mais densa e compacta apresentavam menores valores de solubilidade e permeabilidade e maior força na ruptura.

Ambas as micrografias revelam a presença de orifícios (de aproximadamente $0,1 \mu \mathrm{m}$ ) de forma elíptica que podem ser resultante de dois fatores: a permanência de microbolhas na solução filmogênica comprimidas durante o processo de secagem ou a espaços ocupados por frações de glicerol retiradas da matriz do biofilme durante a aplicação do vácuo. $\mathrm{O}$ efeito do glicerol pode ser observado na topografia da fratura dos biofilmes. O biofilme contendo $30 \%$ de glicerol (Fig. 4) apresentou uma superfície de fratura mais áspera, o que indica a característica mais quebradiça desses biofilmes. Por outro lado, o biofilme contendo $70 \%$ de glicerol (Fig. 5) apresentou uma superfície de fratura mais homogênea.

\section{CONCLUSÕES}

1. As proteínas liofilizadas preparadas do músculo dos peixes são efetivamente constituídas de proteínas miofibrilares, solúveis em baixo $\mathrm{pH}(<4,0)$.

2. As proteínas miofibrilares de tilápia-do-nilo são capazes de formar biofilmes transparentes, homogêneos e flexíveis.

3. Os biofilmes elaborados com as proteínas miofibrilares liofilizadas são resistentes e pouco deformáveis, apresentam baixa solubilidade em água e baixa opacidade, resultantes de uma matriz contínua e densa.

\section{AGRADECIMENTOS}

À FAPESP, pela bolsa de mestrado (96/6244-1) concedida à Ednelí Soraya Monterrey-Quintero e pelo auxílio (95/9315-4); ao programa CAPES/ COFECUB, pelo auxílio (205/97); ao CNPq, pela bolsa concedida a Paulo José do Amaral Sobral.

\section{REFERÊNCIAS}

AN, H.; WEERANSINGHE, V.; SEYMOUR, T.A.; MORRISSEY, M.T. Cathepsin degradation of pacific whiting surimi proteins. Journal of Food Science, v.59, n.5, p.1013-1017, 1994

ASSOCIATION OF OFFICIAL ANALYTICAL CHEMISTS. Official Methods of Analysis of AOAC International. 16.ed. Washington, 1995. p. $4.1 ; 4.4 ; 4.13 ; 31.10$.

CÂNDIDO, L.M. Obtenção de concentrados e hidrolisados protéicos de Tilápia do Nilo (Oreochromis niloticus): composição, propriedades nutritivas e funcionais. Campinas : UniCamp, 1998 207p. Tese de Doutorado.

CUQ, B. Mise en forme et caractérisation de biomatériaux à base de protéines myofibrillaires Montpellier : Université de Montpellier II, 1996a. 213p. Thèse de Doctorat

CUQ, B.;AYMARD, C.; CUQ, J.L.; GUILBERT, S. Edible packaging films based on fish myofibrillar proteins: formulation and functional properties. Journal of Food Science, v.60, n.6, p.1369-1374, 1995.

CUQ, B.; GONTARD, N.; CUQ, J.L.; GUILBERT, S. Functional properties of myofibrillar protein-based biopackaging as affected by film thickness. Journal of Food Science, v.61, n.3, p.580-583, 1996.

CUQ, J.L. Technologie des protéines. Montpellier: Université Montpellier II, 1996b. 200p. Apostila.

FAILEY, P.; MONAHAN, F.J.; GERMAN, J.B.; KROCHTA, J.M. Mechanical properties and water permeability of edible films from whey protein isolate and sodium dodecyl sulfate. Journal of Agricultural and Food Chemistry, v.44, n.2, p.438-443, 1996.

GONTARD, N. Films et enrobages comestibles: étude et amélioration des propriétés filmogènes du gluten. Montpellier : Université de Montpellier II, 1991. Thèse de Doctorat.

GONTARD, N.; GUILBERT, S. Bio-packaging: technology and properties of edible and/or biodegradable material of agricultural origin. Boletim do SBCTA, v.30, n.1, p.3-15, 1996.

HASTINGS, R.J.; RODGER, G.W.; PARK, R.; MAT THEWS, Q.D.; ANDERSON, E.M. Differential scanning calorimetry of fish muscle: the 
effect of processing and species variation. Journal of Food Science, v.50, p.503-510, 1985.

HUF-LONERGAN, E.J.; BEEKMAN, D.D.; PARRISH JUNIOR, F.C. Protein separation and analysis of certain skeletal muscle proteins; principles and techniques. In: HETTIARACHCHY, N.S.; ZIEGLER, G.R. (Eds.). Protein functionality in food systems. New York : Marcel Dekker, 1994. p.79-119.

JIANG, S.-T.; LEE, B.-L.; TSAO, S.-Y.; LEE, J.-J Mackerel cathepsins B and L effects on thermal degradation of surimi. Journal of Food Science, v. 62, n.2, p.310-315, 1997

KUNTE, L.A.; GENNADIOS, A.; CUPPETT, S.L.; HANNA, M.A.; WELLER, C.L. Cast films from soy protein isolates and fractions. Cereal Chemistry, v.74, n.2, p.115-118, 1997.

MEINKE, W.W.; RAHMAN, M.A.; MATTIL, K.F. Some factors influencing the production of protein isolates from whole fish. Journal of Food Science, v.37, p.195-198, 1972.

MONTERREY-QUINTERO, E.S. Caracterização físico-química de proteínas miofibrilares e elaboração de biofilmes. Pirassununga : USP, 1998. 83p. Dissertação de Mestrado

OCUNO, D.; SOBRAL, P.J.A.; SAVASTANO JUNIOR, $H$. Influência do teor de plastificante e do tipo de ácido sobre as propriedades mecânicas de biofilmes à base de proteínas miofibrilares de carne. In: CONGRESSO BRASILEIRO DE CIÊNCIA E TECNOLOGIA DE ALIMENTOS, 7., 1998, Rio de Janeiro. Anais. Rio de Janeiro : SBCTA, 1998. p.2074-2077.

PARK, J.W.; LANIER, T.C. Scanning calorimetric behavior of tilapia myosin and actin due to processing of muscle and protein purification. Journal of Food Science, v.54, n.1, p.49-51, 1989.
PARRIS, N.; COFFIN, D.R.; JOUBRAN, R.F.; PESSEN, $\mathrm{H}$. Composition factors affecting the water vapor permeability and tensile properties of hydrophilic films. Journal of Agricultural and Food Chemistry, v.43, p.1432-1435, 1995.

SHIH, F.F. Edible films from rice protein concentrate and pullulan. Cereal Chemistry, v.73, n.3, p.406-409, 1996.

SOUZA, S.M.A.; SOBRAL, P.J.A.; MENEGALLI, F.C. Desenvolvimento de filmes comestíveis à base de proteínas miofibrilares extraídas de carne bovina. In: WORKSHOP SOBRE BIOPOLÍMEROS, 1997, Pirassununga. Anais. Pirassununga : FZEA-USP, 1997. p.102-106.

STEFANSSON, G.; HULTIN, H.O. On the solubility of cod muscle proteins in water. Journal of Agricultural and Food Chemistry, v.42, p.2656-2664, 1994.

VENUGOPAL, V.; MARTIN, A.M.; PATEL, T.R.; VASANTHAN, T.; OMAR, S. Rheological and solubility characteristics of washed Capelin (Mallotus villosus) mince in water. Journal of Food Biochemistry, v.19, p.175-190, 1995.

VERREZ, V.; CHOPIN, C.; HAN-CHING, L. Propriétés gélifiantes des protéines myofibrillaires du poisson (surimi): l'exemple du tacaud (Trisopterus luscus). In: LORIENT, D.; COLAS, B.; LE MESTE, M. (Eds.). Propriétés fonctionelles des macromolecules alimentaires. Paris : Lavoisier, 1988. p.137-156.

WU, Y.J.; ATALLAH, M.T.; HULTIN, H.O. The proteins of washed, minced fish muscle have significant solubility in water. Journal of Food Biochemistry, v.15, p.209-218, 1991. 